\title{
Understanding Fiber-Matrix Integrity in Fiber-Reinforced Polymer Composites from Strain Rate Sensitivity Concept
}

\author{
Sinebe J. E. ${ }^{1}$, Chukwuneke J. L. ${ }^{2, *}$, Omenyi S. N. ${ }^{2}$ \\ ${ }^{1}$ Department of Mechanical Engineering, Delta State University, Abraka, Nigeria \\ ${ }^{2}$ Department of Mechanical Engineering, Nnamdi Azikiwe University, Awka, Nigeria
}

Received September 19, 2019; Revised March 23, 2020; Accepted June 4, 2020

\section{Cite This Paper in the following Citation Styles}

(a): [1] Sinebe J. E., Chukwuneke J. L., Omenyi S. N. , "Understanding Fiber-Matrix Integrity in Fiber-Reinforced Polymer Composites from Strain Rate Sensitivity Concept," Universal Journal of Mechanical Engineering, Vol. 8, No. 5, pp. 243 - 250, 2020. DOI: 10.13189/ujme.2020.080501.

(b): Sinebe J. E., Chukwuneke J. L., Omenyi S. N. (2020). Understanding Fiber-Matrix Integrity in Fiber-Reinforced Polymer Composites from Strain Rate Sensitivity Concept. Universal Journal of Mechanical Engineering, 8(5), 243 - 250. DOI: 10.13189/ujme.2020.080501.

Copyright $@ 2020$ by authors, all rights reserved. Authors agree that this article remains permanently open access under the terms of the Creative Commons Attribution License 4.0 International License

\begin{abstract}
The understanding of fiber-matrix integrity in fiber-reinforced polymer composites from strain rate sensitivity concept was considered from interfacial energetics point-of-view. The methodology involved the preparation of plantain fibers, treatment of fibers with nine different liquids to render their surfaces hydrophobic, molding of fiber reinforced composites, measurement of contact angles on fibers and composites, composites tensile strength determination, and fiber pullout tests. The results showed that Methyl Ethyl Ketone Peroxide (MEKP) and mercerization $(\mathrm{NaOH})$ rendered the fibers most hydrophobic. MEKP and $\mathrm{NaOH}$ treated fibers gave the lowest surface energies, maximum works of adhesion and hence better fiber-matrix bonding (increased fiber-matrix integrity) when compared with other treatments. The strain-rate sensitivity index, m, obtained ranged from 0.2264 for phosphoric acid-treated fiber in the composite to 0.2385 MEKP treatment fiber with an overall average value of $m$ of 0.2341 , while the value of $m$, for untreated fiber reinforced composite was 0.2321. MEKP and $\mathrm{NaOH}$ treated fibers were most hydrophobic gave the highest $\mathrm{m}$ values and therefore most desired for treatment of fibers for composite formation. The pullout tests result showed that increase in work of adhesion led to an increase in the tensile energy, showing that stronger bonding will guarantee fiber-matrix composite stability and integrity. MEKP and $\mathrm{NaOH}$ with maximum free energies of
\end{abstract}

adhesion also exhibit maximum pullout forces which implied that the bonding between fiber and matrix was stronger for these treatments and hence higher fiber-matrix integrity in the composite. It was also shown that the pull-out force increased with the strain rate sensitivity index confirming that one would need composites with higher $\mathrm{m}$-values for stronger fiber/matrix composites. The results of this work are very important in structures that are made with fiber reinforced composite materials, such as, airplane and car bodies. This work shows that the use of the adhesive energy-stress concept to determine the strain rate is valid since the values of strain rate sensitivity indices calculated are comparable with values reported in the literature and that fiber-matrix integrity can be understood from interfacial free energies and strain rate sensitivity concepts.

Keywords Integrity, Stability, Strain Rate, Fiber-matrix Integrity, Composite, Adhesion, Surface Energy

\section{Introduction}

Ever since the breakthrough and public declaration on the use of carbon fiber five decades ago, much attention has 
been on fiber-reinforced polymer composites especially on the area of composite materials and structures under stress conditions. But surprisingly few have provided an in-depth physical understanding of why composite materials fail leading to the collapse of structures. The missing link is the appreciation of what integrity of a composite represents (Beaumont and Soutis, 2016).

The fiber-matrix interface is a key contributor to non-catastrophic behaviour in a composite (Smolej, et al. 2009; Vimal et al, 2015). If the fiber is weakly bonded to the matrix at fiber-matrix interface (the fiber usually requires a coating), cracks that reach the interface are deflected around the fiber rather than through it (Begum and Islam, 2013; Agus et al, 2015; Peter and Costas 2016). Fiber pullout or composite delamination is indicative of this damage-tolerant behaviour (NRC, 1998; Roslam et al, 2015). Critical issues concerning integrity (i.e. structural) of the composite centre on the mechanism of de-bonding and interfacial properties dependence. Issues of concern also include the optimum surface treatment definition of fiber and optimum properties of any inter-phase between the matrix and fiber or coating. Vital, then, is the integrity of the interface which is dependent on the nature of the interfacial bond (Beaumont and Soutis, 2016; Frank and Douglas, 2018).

These questions, therefore, can arise: What mechanism controls fiber-matrix de-bonding? What fiber surface treatment satisfies the interface properties that will lead to strong fiber-matrix bonding? What role does hydrophobicity of the fiber play in bonding mechanism? (Siregar, et. al. 2010; Ticoalu, et. al., 2010). This paper seeks to address some of these questions by employing strain rate sensitivity and surface energetics approaches to explain the integrity of the fiber in the matrix under loading. The ability of the bond between the fiber and matrix to resist failure is an indication of bond strength and hence of interface integrity. This paper considers, in its simplest form, the relationship between applied stress on the fiber to fiber adhesive energy with the matrix.

\section{Theoretical Considerations}

Theoretically speaking, the integrity of a fiber reinforcement in a polymer matrix depends on the strength of the adhesion of the fiber to the matrix. This suggests a balance between the strength of adhesion of fiber to the matrix and the force trying to pull the fiber from the matrix. If the adhesive strength is greater than the shear strength between fiber and matrix, the fiber remains in the matrix showing high fiber/matrix integrity. But if the adhesive strength is less than the shear strength, there will be fiber pullout or delamination, i.e., fiber failure, showing poor fiber/matrix integrity.

Let us consider the relationship between fiber pull strength i.e., the tensile strength, and fiber adhesive energy and present the ratio as

$$
R=\frac{\text { Work of Adhesion }}{\text { Tensile Strength }}
$$

Dimensionally, eq. (1a) gives $R \equiv \frac{\mathrm{mJ} / \mathrm{m}^{2}}{\mathrm{~N} / \mathrm{mm}^{2}} \equiv 10^{-9} \mathrm{~s}^{-1}$

Where the work of adhesion is in $\mathrm{mJ} / \mathrm{m}^{2}$ and the tensile strength is in $\mathrm{N} / \mathrm{mm}^{2}$.

One can see therefore that $R$ has the unit of strain rate and eq. (1a) can thus be written as

$$
\text { Strain rate }=\frac{\text { Work of Adhesion }}{\text { Tensile Strength }}
$$

Thus, if eq. (1b) is evaluated it should give the strain rate of the fiber relative to the matrix.

Linking work of adhesion (derived from interfacial free energies) with strain rate is supported by the work of Nwodo, et. al. (1988) who studied the effects of interfacial free energy on creep of polyethylene in sodium dodecyl sulphate (SDS) surfactant solution and showed strain rate to vary with interfacial free energy as shown in Fig. 1. Fig. 1 gives a complex behavior because of the use of a surfactant. The lowest portion gives the point of critical micelle formation.

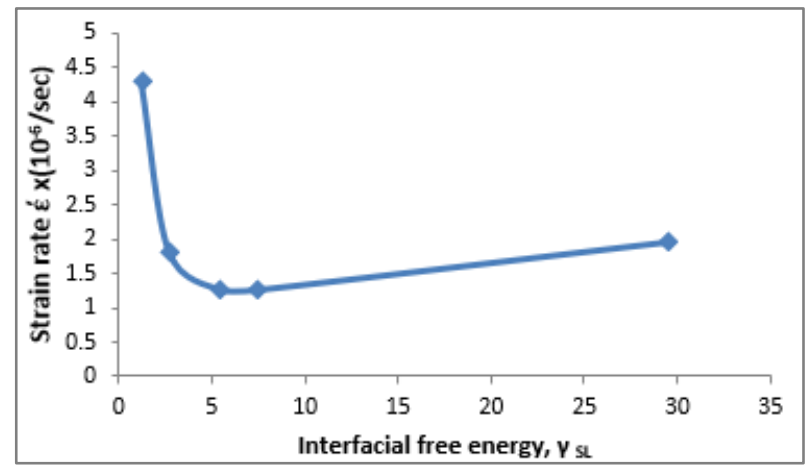

Figure 1. The Relationship between Strain Rate and Interfacial Free Energy for Polypropylene (Source: Nwodo, et. al. 1988)

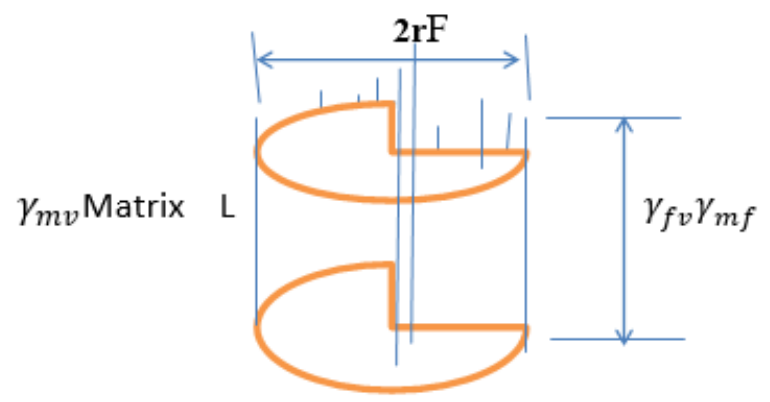

Figure 2. Schematic Diagram of Fibersin Matrix

Consider fig. 2 with fibers in the matrix. At the interface between the fiber and the matrix, the adhesive energy $\left(\Delta F^{a d h}\right)$ between fiber $(f)$ and matrix $(m)$ can be determined using the expression (Sinebe, 2019):

$$
\Delta F^{a d h}=\gamma_{m f}-\gamma_{m v}-\gamma_{f v}
$$

Where $\gamma$ is the interfacial surface energy in $\mathrm{mJ} / \mathrm{m}^{2}$ and the tensile strength is in $\mathrm{N} / \mathrm{mm}^{2}$. 
Eq. (2) in effect is saying that the work of adhesion is equal to the change in free energy resulting from the replacement of the surfaces of the fiber and the matrix exposed to air with a new interface of fiber-matrix. This is the same as saying that, as contact is established between fiber surface and matrix surface, a new fiber/matrix surface area is created while fiber surface area and matrix surface area are 'destroyed'. Changes in surface areas lead to changes in surface free energies.

Further consideration shows that the stress-strain rate behaviour of metals at low temperatures as reported by Backofen, et. al. (1964) obeys the power-law relationship:

$$
\sigma=\left[\mathrm{k}^{\prime}\right]_{\varepsilon, \mathrm{T}}
$$

This is a characteristic equation that describes superplastic behavior where $\sigma=$ flow stress; $\dot{\varepsilon}=$ strain rate; $m=$ strain-rate sensitivity index $(0<m<1)$ which is a function of the forming parameters such as strain rate and temperature and is associated with microstructural characteristics; $k$ is a dynamic modulus.

The most important mechanical characteristic of a superplastic material (Smolej, et. al., 2009) is its high strain rate sensitivity of flow stress. The characteristic equation which describes the superplastic behavior is also as in eq. (3). A material is usually considered to be superplastic under conditions where it displays an $m$ value $>0.3$. An important feature of superplastic alloys is that their flow stresses are low compared with those of conventional materials. During tensile deformation, the effect of a high $m$ is to inhibit catastrophic necking. The $m$ values of commercial superplastic alloys lie in the range of 0.4-0.8.

In a structural member under load, it is important to indicate the extent to which the load would have diminished over time. This is measured by a parameter, $m$, called strain rate sensitivity index, given in eq. (4), at constant strain, $\epsilon$, and temperature, $T$ (Hart, 1967; Gobble and Wolff, 1993; Mohammadzadeh et al, 2014):

$$
m=[\partial \ln (\sigma)] /[\partial \ln (\dot{\epsilon})]_{\epsilon, \mathrm{T}}
$$

Where $\sigma=$ stress, $\dot{\varepsilon}=$ strain rate and it is assumed that the conditions approximate a steady-state process. In principle, the strain-rate sensitivity index can also be determined by stress-relaxation testing.

Whereas eq. (1) measures the strain rate as calculated from a relationship between work of adhesion and tensile stress, eq. (4) gives the strain rate sensitivity index calculated from the tensile stress and strain rate. It is important to note that, eq. (4) has been successfully used to determine the strain rate sensitivity index of several thermoplastics materials (Gobble and Wolff, 1993).

\section{Materials and Methods}

The fiber material used in this study is the plantain fiber. It was extracted from plantain pseudostem using the manual scraper (Sinebe et al, 2019; Ray et al, 2013; Tingju et al, 2013); it was prepared and treated with the following liquids: acetylation (Dhanalakshmi et al., 2012; Bledzki et al, 2008), acetone(Samal, (2012), glycerol, hydrogen peroxide, MEKP, mercerization $(\mathrm{NaOH})$ (Siregar et al., (2010), methanol(Aleksandra et al., 2011), potassium permanganate (Dhanalakshmi et al., 2012). and phosphoric acid, with the aim of selecting the best treatment that would make the fiber most hydrophobic.

The matrix material used was polyester resin. The composite material was prepared in cylindrical forms, (Sinebe, 2019). To be able to characterize the surfaces for adhesive energy determination, contact angles were measured on both the fiber and on the matrix materials by means of a special microscope (HD colour CMOS sensor, high-speed DSP) using water and glycerol as probe liquids. Interfacial free energies were calculated from contact angles by methods of Neumann (1975) and Fowlkes (1968) and the average values were obtained (Chukwuneke et al, 2015) with which the work of adhesion (Chukwuneke et al, 2017) was calculated for each treated material using eq. (2).

The tensile strengths of untreated and treated fiber reinforced polymer composites were determined via a Universal testing machine using the ASTM D638 guidelines. The fiber pull-out from the fiber-matrix composite was carried out on the untreated, and $\mathrm{NaOH}$ and MEKP treated plantain fibers in accordance to Lei et al, (2014) to establish the force and elongation at pullout using Multifunctional Electric Fabric Strength Machine (Machine Model- YG026D).

\section{Results and Discussion}

The average contact angle values and surface energies of treated and untreated fibers, and changes in free energies of adhesion for untreated and treated fiber reinforced polymer composites using nine treatment liquids for each test probe liquid (water and glycerol) are summarized in Table 1.

Table 1. Average Contact Angles, Surface Energies and Changes in Free

\begin{tabular}{|c|c|c|c|c|}
\hline \multicolumn{2}{|r|}{ Test Liquid } & $\begin{array}{c}\text { Contact } \\
\text { Angle }\end{array}$ & $\begin{array}{c}\text { Surface } \\
\text { Energies } \\
\left(\mathrm{mJ} / \mathrm{m}^{2}\right)\end{array}$ & $\begin{array}{c}\Delta F^{\text {adh }} \\
\left(\mathrm{mJ} / \mathrm{m}^{2}\right)\end{array}$ \\
\hline \multicolumn{2}{|r|}{ Untreated Fiber } & 55.40 & 40.02 & -40.24 \\
\hline \multicolumn{2}{|r|}{ Matrix } & 57.40 & 40.97 & - \\
\hline \multirow{9}{*}{ 冚 } & Acetylation & 65.30 & 32.53 & -42.23 \\
\hline & Acetone & 70.20 & 33.50 & -44.22 \\
\hline & Glycerol & 64.10 & 32.48 & -40.89 \\
\hline & $\begin{array}{l}\text { Hydrogen } \\
\text { Peroxide }\end{array}$ & 67.70 & 32.41 & -42.25 \\
\hline & $\begin{array}{l}\text { Mercerization } \\
(\mathrm{NaOH})\end{array}$ & 71.30 & 31.55 & -45.73 \\
\hline & MEKP & 73.00 & 31.24 & -46.04 \\
\hline & Methanol & 61.00 & 36.47 & -42.60 \\
\hline & $\begin{array}{c}\text { Potassium } \\
\text { Permanganate }\end{array}$ & 62.70 & 33.93 & -41.90 \\
\hline & Phosphoric Acid & 60.40 & 36.93 & -37.67 \\
\hline
\end{tabular}
Energy of Adhesion for Untreated and Treated Fiber 
Tables 1 shows that treated fiber has higher measured contact angle than the untreated fiber in all cases. Thus, fiber treatment tends to make the fibers to be poorly wetted, i.e., there is increase in the hydrophobicity of the fibers with each treatment liquid. The fibers treated with Methyl ethyl ketone peroxide (MEKP) gave the highest contact angles followed by $\mathrm{NaOH}$ treated fibers. The phosphoric acid-treated fiber presents the lowest fiber contact angle though it is higher than the untreated fiber contact angle by about $8 \%$. The lowest contact angle differs from the highest contact angle for treated fibers by about $17 \%$.

The average surface free energies of untreated fibers is $40.02 \mathrm{~mJ} / \mathrm{m}^{2}$ which is higher than the average surface free energies of treated fibers implying that these fiber treatment liquids have surface energy reducing ability. The surface free energies of treated fibers vary from $31.24 \mathrm{~mJ} / \mathrm{m}^{2}$ for MEKP to $36.93 \mathrm{~mJ} / \mathrm{m}^{2}$ for Phosphoric Acid. MEKP, $\mathrm{NaOH}$ and Phosphoric Acid treatment reduced the surface energies of the fibers by about $22 \%, 21 \%$ and $7.7 \%$ respectively when compared with those of untreated fibers.

MEKP which gives the lowest fiber surface free energy is most hydrophobic and so it is preferred for fiber surface treatment over $\mathrm{NaOH}$ which gives the next lowest surface free energy. $\mathrm{NaOH}$ has hitherto been generally used to render surfaces of fibers hydrophobic but this result shows that MEKP is more preferable. The free energies of adhesion (Table 1) calculated using eq. (2), are all negative showing that the net van der Waals forces are attractive, confirming interfacial bonding of fiber to the matrix. Fiber treated with MEKP gives the highest free energy of adhesion, also confirming that rendering fibers hydrophobic helps to increase their adhesion to matrix surfaces. Treatment of fibers leads to decrease in hemicelluloses and lignocelluloses properties which in turn lead to increase in attractive van der Waals forces as the surface area at the phase boundary and surface energy are reduced.

Table 2 shows that the MEKP and $\mathrm{NaOH}$ treated fibers in the fiber-matrix composite have the highest ultimate tensile strength (UTS), and the highest free energy of adhesion, showing that fiber treatment increases the strength of the fiber-reinforced composite. It can thus be stated that increase in the adhesive bonding leads to an increase in the tensile strength of the composite. Phosphoric Acid treated fiber composite with the lowest free energy of adhesion also has the lowest tensile strength, as expected. It is interesting to note that Glycerol and Methanol treated fiber reinforced composites exhibit tensile strength closer to that of the untreated fiber reinforced composite, showing that these treatments do not significantly affect the strength of the fiber reinforced composite.

The tensile strength of the unreinforced polyester gives the lowest tensile strength of $148.12 \mathrm{~N} / \mathrm{mm}^{2}$ which is lower than those for Phosphorus acid and MEKP treated fiber reinforced composites by $0.44 \%$ and $34 \%$, respectively. The tensile strength of the untreated fiber reinforced composite is $15.4 \%$ lower than that of MEKP treated fiber composite showing clearly the positive effect of surface treatment of the fiber on the composite strength. Phosphoric acid and Potassium Permanganate treated fiber composites have tensile strengths $13.9 \%$ and $13.5 \%$ respectively lower than that of untreated fiber reinforced polymer composite. This reduction in strength follows from the fact that the free energies of adhesion for Phosphoric Acid and Potassium Permanganate treated fiber reinforced composites are lower than the free energies of adhesion of untreated fiber reinforced composites (see table 1 ) by $7.7 \%$ and $15.2 \%$ respectively.

The strain rates, calculated using eq. (1b), shown on table 2, vary from $0.2225 \times 10^{-9} \mathrm{~s}^{-1}$ for Acetone treatment to $0.2540 \times 10^{-9} \mathrm{~s}^{-1}$ for Potassium Permanganate and Phosphoric Acid treatments. These values measure the rate at which the distances of adjacent parcels of the material change with time in the vicinity of that fiber. Polymer materials exhibit this time-dependent behaviour in a load-bearing material. This is a viscoelastic phenomenon, which, in thermoplastics is of significant importance to the design process in applications where the material is subjected to loading at a constant level of deformation for a prolonged time, such as filaments in tension and seals in compression (Gobble and Wolff, 1993; Sripathi and Padmanabhan, 2016).

The low values of strain rates $\left(\sim 10^{-9} \mathrm{~s}^{-1}\right)$ show that relative movements between the fiber and matrix, and also within the composite, are possibly very low and that Potassium Permanganate and Phosphoric Acid treated systems with higher strain rates are most probable to fail than the Acetone, hydrogen peroxide and MEKP treated fiber reinforced composites. The strain rate for untreated fiber reinforced composite is of the same order of magnitude as those for Phosphoric Acid and Potassium Permanganate treated fiber reinforced composite. This raises the question as to the implication of strain rate to fiber/matrix integrity. Low strain rates may imply low relative movements of fibers in the matrix, suggesting that the fibers are unlikely to pull out and so maintain their integrity in the composite. The strain rate for the fiber reinforced polymer matrix was of the order of $10^{-9} / \mathrm{sec}$ while that reported in the literature for polypropylene was of the order of $10^{-6} / \mathrm{sec}$. 
Table 2. Average UTS, $\Delta \mathrm{F}^{\text {adh }}$, Strain Rate Sensitivity Index and Strain Rate of Treated and Untreated Fibres

\begin{tabular}{|c|c|c|c|c|c|c|c|c|c|}
\hline \multirow{12}{*}{$\begin{array}{c}\text { Untreated, } \\
\text { Treated and } \\
\text { Unreinforced } \\
\text { Polyester }\end{array}$} & Samples & \multirow{12}{*}{$\begin{array}{c}\sigma-\text { UTS } \\
\left(\mathbf{N} / \mathbf{m m}^{2}\right)\end{array}$} & Ave & \multirow{12}{*}{$\Delta \mathbf{F}^{\mathrm{adh}}\left(\boldsymbol{m} J / m^{2}\right)$} & Ave & \multirow{12}{*}{$\begin{array}{c}\text { Strain } \\
\text { rate } \dot{\varepsilon} \\
\left(\mathbf{1 0}^{-9} \mathrm{~s}^{-1}\right)\end{array}$} & Ave & \multirow{12}{*}{$\begin{array}{c}\text { Strain } \\
\text { rate } \\
\text { Sensitivity } \\
\text { Index, m }\end{array}$} & Ave \\
\hline & Untreated & & 171.98 & & -40.242 & & 0.2348 & & 0.2321 \\
\hline & Acetone & & 190.41 & & -42.227 & & 0.2225 & & 0.2362 \\
\hline & Acetylation & & 186.63 & & -44.223 & & 0.2367 & & 0.2359 \\
\hline & Glycerol & & 177.07 & & -40.887 & & 0.2329 & & 0.2334 \\
\hline & $\begin{array}{c}\text { Hydrogen } \\
\text { Peroxide }\end{array}$ & & 185.25 & & -42.246 & & 0.2288 & & 0.2352 \\
\hline & Mercerization & & 194.43 & & -45.726 & & 0.2359 & & 0.2377 \\
\hline & MEKP & & 198.49 & & -46.044 & & 0.2326 & & 0.2385 \\
\hline & Methanol & & 179.29 & & -42.605 & & 0.2384 & & 0.2342 \\
\hline & $\begin{array}{c}\text { Potassium } \\
\text { Permanganate }\end{array}$ & & 165.51 & & -41.899 & & 0.2540 & & 0.2312 \\
\hline & Phosphoric Acid & & 148.84 & & -37.671 & & 0.2540 & & 0.2264 \\
\hline & $\begin{array}{l}\text { Unreinforced } \\
\text { Polyester }\end{array}$ & & 148.18 & & - & & - & & - \\
\hline
\end{tabular}

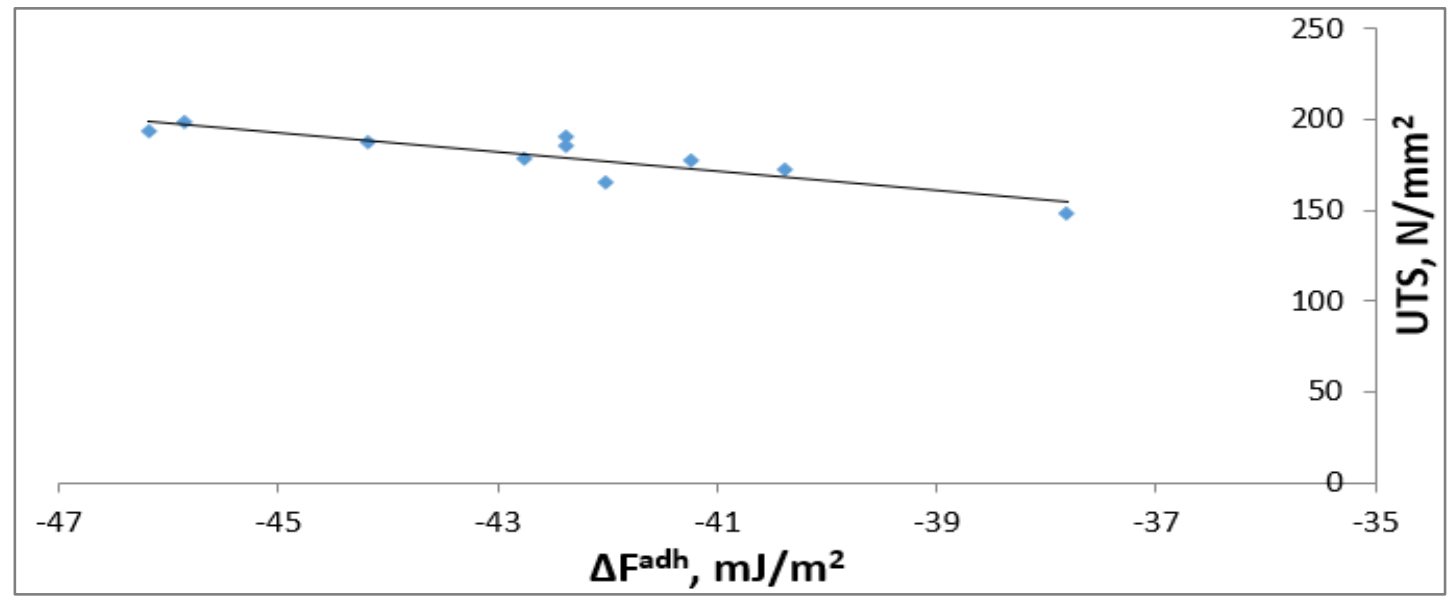

Figure 3. The effect of adhesive bonding on the tensile strength of composite

The strength of the bond between the fiber and matrix was seen to be of paramount importance because that would determine whether the fiber would just pull out or remain in the matrix. The result of the analysis showed that the increase in work of adhesion led to an increase in the tensile energy, as expected and shown in Figure 3. Stronger bonding will guarantee the integrity of the fiber-matrix composite. Figure 3 shows that increases in free energy of adhesion (i.e. increasing in bonding energy) leads to an enhanced tensile strength of the composite and hence on fiber/matrix composite stability. The relationship between the tensile strength and free energy of adhesion is obtained from fig. 3 as:

$$
\sigma=-46.124-5.314 \Delta F^{a d h}
$$

Where $\sigma$ is in $N / \mathrm{mm}^{2}, \Delta F^{\text {adh }}$ is in $\mathrm{mJ} / \mathrm{m}^{2}$, and $R^{2}=0.798$, i.e., about $80 \%$ (i.e., $\mathrm{R}^{2}=0.80$ ) of the data can be predicted by the regression line.

To determine the extent to which the tensile load would have diminished over time, the strain rate sensitivity index, $\mathrm{m}$, was calculated with eq. (4) and listed in table 2. It ranges from 0.2264 to 0.2385 for Phosphorus Acid and MEKP treated fiber reinforced polymer composites, respectively. For the untreated fiber reinforced composite, the sensitivity index is 0.2321 . MEKP and $\mathrm{NaOH}$ treated fiber reinforced composites have the highest m-values and therefore most desired for treatment of fibers for composite formation. Gobble and Wolff (1993) reported that $m$ varied from 0.0260 to 0.687 for Polyvinyl Chloride (PVC) and from 0.1291 to 0.1316 for high-density polyethene (HDPE). Smolej, et. al. (2009), reported that the m-values, determined based on the true stress, true strain curves and also using the jump-test method, varied from 0.35 to 0.70 , which depended upon the forming conditions. Majidi, et. al. (2017) also demonstrated that the m-value is not constant and is highly dependent on the applied strain rate, strain level and testing method. The fact that $m$ for the better treatment liquids is higher than for the untreated fiber suggests that strain rate sensitivity index is a property to be preferred in the study of fiber-matrix integrity than plane strain rate (Nwodo, et. al. 1988; Fuguet et. al. 2005).

The values of $m$ calculated in this work are somehow larger in many cases. Taking the upper limits, the value reported in this work for the polyester composite is $10.44 \%$ higher than that calculated from data of Nwodo et.al. (1988) for polypropylene. The result of this work is also higher than that reported by Gobble and Wolff (1993) for high-density polyethylene (HDPE) by $44.8 \%$. The differences could be attributable to variation in material type, fiber surface treatment fiber reinforcement. 


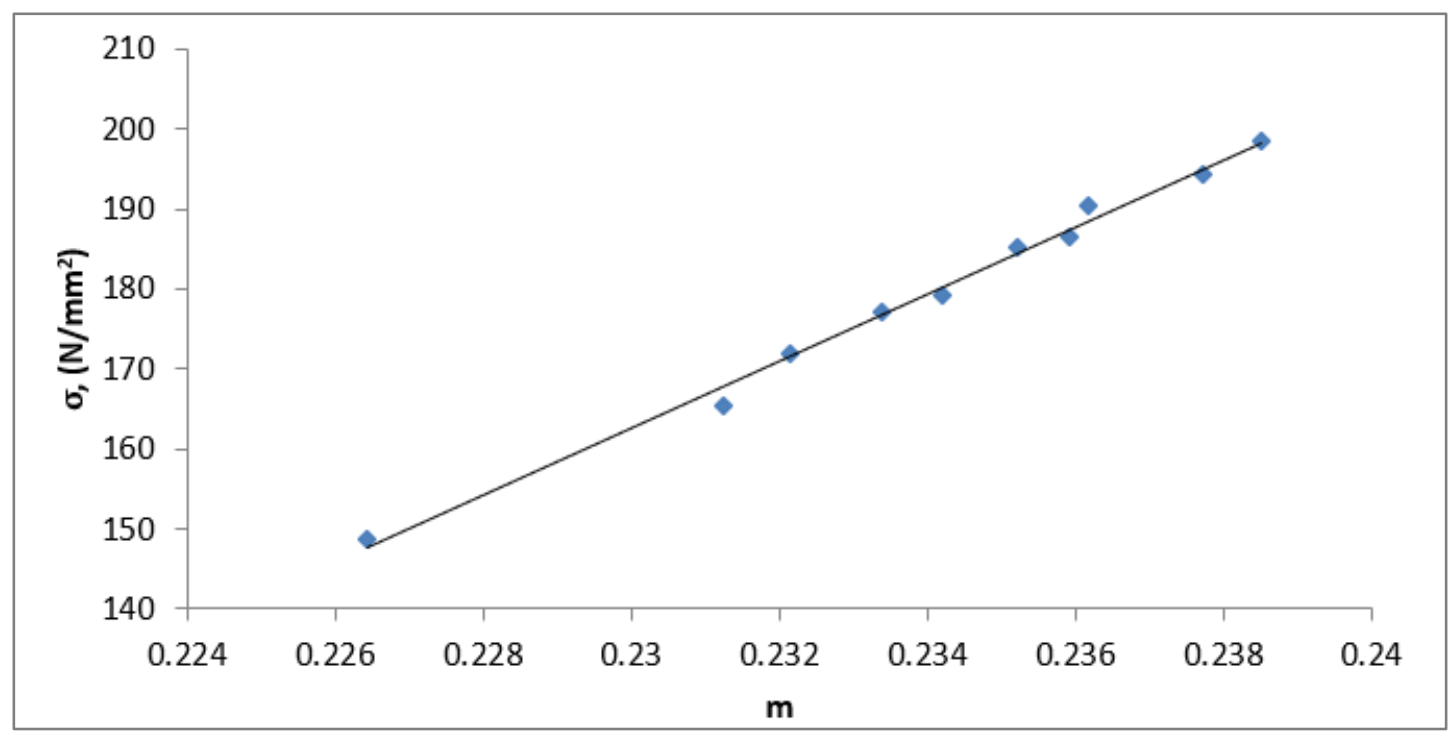

Figure 4. The Relationship between Stress and Strain-rate Sensitivity Index

The relationship between the tensile strength and the strain-rate sensitivity index, $m$, is shown in Figure 4 and mathematically given as

$$
\sigma=4179.7 \mathrm{~m}-798.67
$$

Where the value of $R^{2}=0.9935$ shows that the stress and the strain-rate sensitivity index are strongly correlated. This graph shows that increasing $m$ leads to an increase in bond strength which then results in tougher composite, fiber-matrix stability, and thus improved fiber/matrix integrity.

For fiber reinforced composite to maintain its integrity and remain as a strong composite, the bonding between fiber and matrix must be strong enough to resist delamination, pull-out or separation during usage. It becomes important therefore that a fiber micromechanical testing experiment be performed on the fiber in the composite to determine the extent of its bonding integrity. Fiber pullout test and micro bond test, etc, satisfy this requirement (Lei et al., 2014). In this work, untreated and $\mathrm{NaOH}, \mathrm{MEKP}$ and Phosphoric Acid treated fibers were considered and the results obtained from the experiment are shown in table 3 together with the corresponding free energy of adhesion (the bonding energy) for treated and untreated fibers considered.

Table 3. Pullout Force and Corresponding Energy of Adhesion

\begin{tabular}{|c|c|c|}
\hline Treatment & $\begin{array}{c}\text { Free Energy of Adhesion } \\
\left(\mathbf{m J} / \mathbf{m}^{\mathbf{2}}\right)\end{array}$ & $\begin{array}{c}\text { Pull-out Force } \\
\text { (N) }\end{array}$ \\
\hline Untreated & -40.2416 & 7.215 \\
\hline Merczerization & -45.7257 & 8.215 \\
\hline MEKP & -46.0443 & 8.775 \\
\hline Phosphoric Acid & -37.6706 & 7.57 \\
\hline
\end{tabular}

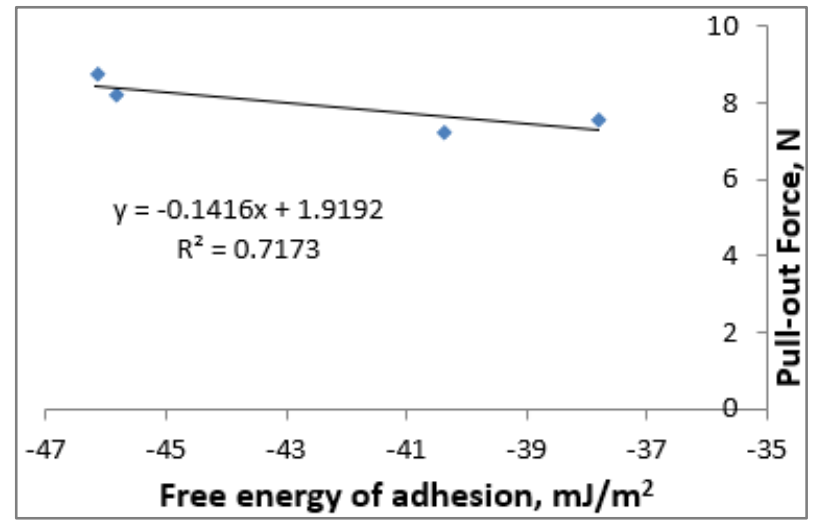

Figure 4a. Pullout Force Compared with Free Energy of Adhesion

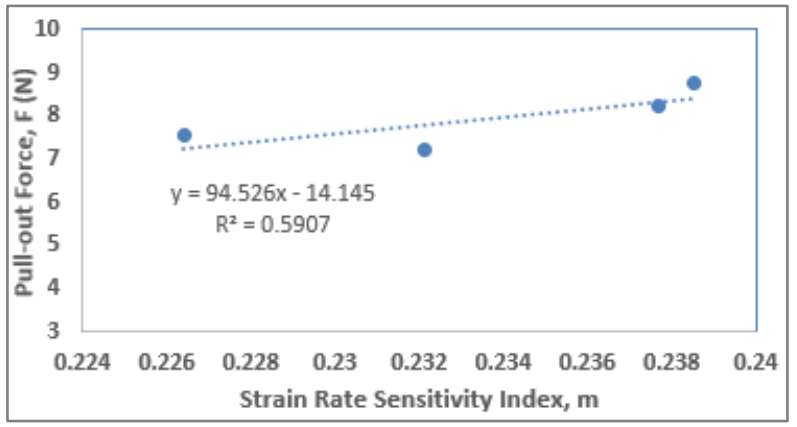

Figure 4b. Pullout Force Compared with Strain Rate Sensitivity Index, $\mathrm{m}$.

Table 3 shows that fiber surface treatment increases the pullout force at the same time that the free energy of adhesion is increased, over and above values for untreated fiber. MEKP and $\mathrm{NaOH}$ with maximum free energies of adhesion also exhibit maximum pullout forces. These high forces imply that the bonding between fiber and matrix was stronger for these treatments and so will assure higher fiber-matrix integrity in the composite. 
Fig. 4a shows clearly that as the free energy of adhesion is increased (increased interfacial bond), the pullout force also increases as expected. Fig. 4b shows that as the strain rate sensitivity index is increased, the pullout force increases. The increase in pullout force is as a result of increase in adhesive bonding between fiber and matrix, and this leads to increase in fiber-matrix integrity.

\section{Conclusions}

The integrity of the bonded fiber-matrix interface was considered from interfacial energetics point of view. MEKP and $\mathrm{NaOH}$ treatments of the fiber give enhanced fiber and matrix bonding (increased fiber-matrix integrity). The correlation connecting the tensile strength and free energy of adhesion showed that increase in free energy of adhesion (increasing in bonding energy) leads to an increase in tensile strength of the composite and hence on fiber-matrix composite stability. Understanding of the fiber-matrix integrity was considered from the strain rate and strain rate sensitivity approach. The low values of the strain rate suggest that the fiber sliding against the polymer matrix to which it was bonded was infinitesimally low and would not cause a noticeable change in the bonding. Fiber-reinforced polymer composite structures for industrial applications would be more reliable if they show little or no deformation under load with time making the fiber reinforced matrix a very good material for industrial applications.

Since the strain rate sensitivity index, $\mathrm{m}$, in this study is less than 0.30 , it can be surmised that the reinforced plastic is relaxed and so would not be adversely subjected to stress build-up at the interface between the fiber and the matrix. This work also shows that the use of adhesive energy concept to determine the strain rate is valid since the values of strain rate indices evaluated are comparable with values reported in the literature. MEKP and $\mathrm{NaOH}$ treated fibers show that they are the most hydrophobic; they also have the highest m-values and therefore most desired for treatment of fibers for composite formation. Increasing $\mathrm{m}$ through an increase in bond strength results in tougher composite and hence on fiber-matrix stability. The high pull-out forces observed (MEKP and $\mathrm{NaOH}$ ) imply that the bonding between fiber and matrix was stronger for these treatments and so will assure higher fiber-matrix integrity in the composite.

The results of this research are extremely important in structures that are made with fiber reinforced polymer composites. Fiber-reinforced polymer composites used in manufacturing industries, should be regularly checked to ascertain that the composite maintains its integrity and that there is no fiber delamination. To obtain fiber reinforced composites for application in auto-bodies or in construction, the fibers should be treated with MEKP and such that higher m-values are obtained.

\section{REFERENCES}

[1] Agus E. P., Indriyani R., Anne Z., Subyakt O. (2015). Tensile and Shear punch Properties of Bamboo Fibres Reinforced Polymer Composites. International Journal of Composite Materials, 5(1): 9-17.

[2] Aleksandra A.P., PuzachenkoA.Yu., Soldatova I,B. (2011). Morphological Diversity of Wing Structure in Rhinolophoidea Bats (Chiroptera, Rhinolophoidea). Biology Bulletin, 38(7): 1 - 16 .

[3] Backofen, W.A., Turner, I.R. and Avert, D.H. (1964). Superplasticity in an Al-Zn alloy. Trans. Am. Soc. Metals., 57: 980 - 990 .

[4] Beaumont W. R. Peter, Soutis Costas (2016): Structural integrity of engineering composite materials: a cracking good yarn, Phil. Trans. Royal Soc., A374: 20160057. DOI: 10.1098/rsta.2016.0057.

[5] Begum K., Islam M. A. (2013). Natural Fibre as a substitute for Synthetic Fibre in Polymer Composite: A Review. Research Journal of Engineering Science, 2(3): 46-53.

[6] Bledzki A.K., Mamun A.A., Lucka-Gabor M. and Gutowski V.S., (2008) The effects of acetylation on properties of flax fibre and its polypropylene composites, Express. Polym. Lett.,2(6):413 - 422.

[7] Chukwuneke JL, Achebe CH, Omenyi SN. (2015). Surface Thermodynamics Approach to Mycobacterium tuberculosis (M-Tb) - Human Sputum Interactions. J Bioengineer \& Biomedical Sci, 5: 167. doi:10.4172/2155-9538.1000167.

[8] Chukwuneke L. Jeremiah, Achebe H. Chinonso, Sinebe E. Jude, Ugwuegbu C. Duke (2017). Surface Energetics Effects of Human Immunodeficiency Virus Co-infection on Mycobacterium Tuberculosis - Macrophage Interaction Mechanism. J Appl Biotechnol Bioeng, 3(6):00088. DOI:10.15406/jab.2017.03.00088.

[9] Dhanalakshmi S., Ramadevi P., Srinivasa C. V. and Bennehalli, B., (2012). Effect of chemical treatment on water absorption of areca fiber. Journal of Applied Sciences Research, 8(11): 5298-5305.

[10] Fowkes, F. M. (1968). Calculation of Work of Adhesion by Pair Potential Summation. J. Colloid Interface Sci, 28: 493.

[11] Frank M. E., Douglas G. (2018). Surface Free Energy Deermination of Powders and Particles with Pharmaceutical Applications: A critical Review. Reviews of Adhesion and Adhesives, 6(3): 329 - 367. doi.org/10.7569/RAA.2018.097 310.

[12] Fuguet Elisabet, Clara Ràfols, MartíRosésand, Elisabeth Bosch, (2005), Critical micelle concentration of surfactants in aqueous buffered and unbuffered systems. AnalyticaChimicaActa,548 (1-2): 295 - 100.

[13] Goble, D.L. and E.G. Wolff (1993), Strain rate sensitivity index of thermoplastics. Journal of Material Science, 28 (22): 5986 - 5994.

[14] Hart, E.W. (1967), Theory of tensile test. Acta Metall., 15: $351-355$. 
[15] Lei, Zhenkun; Xuan Li; Fuyong Qin and Wei Qiu (2014), Interfacial Micromechanics in Fibrous Composites: Design, Evaluation, and Models. The Scientific World Journal, 2014: 9.doi.org/10.1155/2014/282436.

[16] Majidi O., Mohammad J., Nicolas B., and Ehab S. (2017) Variation of strain rate sensitivity index of a superplastic aluminum alloy in different testing methods, AIP Conference Proceedings 1896, 020022 (2017); https://doi.o rg/10.1063/1.5007979

[17] Mohammadzadeh A., Azadbeh M., Danninger H. (2014). New concept in analysis of supersolidus liquid phase sintering of alpha brass. Powder Metallurgy, 58(2): 123 132, doi:10.1179/1743290114Y.0000000114.

[18] National Research Council (NRC). 1998. Ceramic Fibres and Coatings: Advanced Materials for the Twenty-First Century.Washington, DC: The National Academies Press., doi: 10.17226/6042.

[19] Neumann, A.W., Hope, C.J., Ward, C.A., Herbert, M.A., Dunn, G.W., and Zingg, W., (1975). The Role of Surface Thermodynamics in thromboresistance of Biomaterials. $J$. Biomed. Mater. Res., 9: 127 - 142.

[20] Nwodo, E.E.; V.O. Nkado and S.N. Omenyi (1988). Effects of interfacial free energy on creep of polypropylene specimens. 6th. Annual Conference of the Nigerian Metallurgical Society, Enugu, November 3-5, 1988.

[21] Peter W. R. Beaumont and Costas Soutis (2016). Structural Integrity of Engineering Composite Materials: A Cracking good yarn. Philosophical Transactions of the Royal Society A: Mathematical, Physical and Engineering Sciences, 374(2071): doi.org/10.1098/rsta.2016.0057.

[22] Ray D, Nayak L, Ammayappan L, Shambhu V, Nag D. (2013). Energy conservation derives for efficient extraction and Utilization of banana fibre. Int. J. of Emerging Technology and Adv. Engineering, 3: 296 - 310.

[23] Roslan S.A.H., Rasid Z.A., Hassan M.Z. (2015). The Natural Fiber Composites based on Bamboo Fibers: A Review. ARPN Journal of Engineering and Applied Sciences, 10(15): $6279-6288$.

[24] Samal, S. K., Mohanty, S., and Nayak, S. K, (2012). Banana-glass fibre-reinforced polypropylene hybrid composites: Fabrication and performance evaluation. Polymer-Plastics Technology and Engineering, 48(4): 397-
414.

[25] Sinebe J.E. (2019). Fibre-matrix integrity in fibre-reinforced polymer composites. Nnamdi Azikiwe University, Awka, Nigeria, $\mathrm{PhD}$ Thesis.

[26] Sinebe J.E., Chukwuneke J.L., Omenyi S.N. (2019). Surface Energetics Effects on Mechanical Strength of Fiber Reinforced Polymer Matrix. Journal of Physics: Conference Series, 1378, 042016: 1 - 8. DOI: 10.1088/1742-6596/1378 /4/042016.

[27] Sinebe J.E., Chukwuneke J.L., Omenyi S.N. (2019). Implications of Interfacial Energetics on Mechanical Strength of Fibre Reinforced Polymer Matrix. International Journal of Material Engineering, 9(1): 1 - 7. DOI: 10.5923/j.ijme.20190901.01.

[28] Siregar J.P., Sapuan, S. M., Rahman, M. Z. A., and Zaman, H. M. D. K., (2010). The effect of alkali treatment on the mechanical properties of short pineapple leaf fibre (PALF) reinforced high impact polystyrene (HIPS) composites. Journal of Food, Agriculture \& Environment., 8 (2): 1103 1108.

[29] Smolej Anton, BraneSkaza and MatevžFazarinc (2009). Determination of the strain-rate sensitivity and the activation energy of deformation in the superplastic aluminium alloy, RMZ - Materials and Geoenvironment, 56 (4): 389 - 399.

[30] Sripathi S. and Padmanabhan K. A. (2016). Universality of the Phenomenology of Structural Superplasticity. Materials Science Forum, 838-839: 84 - 88.

[31] Ticoalu A., Aravinthan T. and Cardona F., (2010) A review of current development in natural fibre composites for structural and infrastructure applications. Proceedings of Southern Region Engineering Conference(SREC), (Toowoomba, Australia), (2010).

[32] Tingju L., Man J., Zhongguo J., David H., Zeyong W., Zuowan Z. (2013). Effect of Surface Modification of Banana Cellulose Fibres on Mechanical Properties of Cellulose/Epoxy Composites. Composites: Part B, 51: 28 34.

[33] Vimal R., Hari Hara Subramanian K., Aswin C., Logeswaran V., Ramesh M. (2015). Comparisonal study of succinylation and phthalicylation of jute fibres: study of Machanical properties of modified fibre reinforced epoxy composites. Materialstoday: Proceedings, 2(4): 2918 - 2927, doi.org/10.1016/j.matpr.2015.07.254. 